\title{
Synthesis and spectral characterization of some bromo-benzothiazolo pyrazolines
}

\author{
Bharat Kumar ${ }^{1}$, Vishal Pathak ${ }^{2}$, Sushma Rani ${ }^{3}$, Ravi Kant ${ }^{4}$ and Tiwari I.C. ${ }^{1^{\star}}$ \\ ${ }^{1}$ Department of Chemistry, D.B.S. (P.G.) College, Kanpur-208 001, UP \\ ${ }^{2}$ Department of Chemistry, Paliwal (P.G.) College, Shikohabad-205135, UP \\ ${ }^{3}$ Department of Chemistry, D.G. (P.G.) College, Kanpur-208 001, UP \\ ${ }^{4}$ Department of Medicinal Chemistry, Mahatma Gandhi Institute of Pharmacy, Lucknow-227101, UP
}

\begin{abstract}
The present investigation deals with the synthesis of some bromo-benzothiazolopyrazolines from substituted pyrazolines. The synthesized bromo benzothiazolopyrazolines were characterized by elemental analyses, IR, NMR and mass spectra. The fragmentation pattern of one of the compound has also been suggested.
\end{abstract}

\section{Introduction}

In view of the influence of halogen atoms on the biological activity of organic compounds, Ankhiwala [1] synthesized some nuclear halogenated pyrazolines and their derivatives and screened them for their biological activity. These compounds were found to be active against Staphylococcus aureus and Escherichia coli. Wolf [2] synthesized $\mathrm{N}_{1}$ Aryloxyacetal-3-methyl-5-pyroziline. Reactions with these pyrazolines gave monoaryllidene derivatives along with bis-pyrazolone. Monoarylidine compounds were brominated with bromine in acetic acid to give 4bromo (4- $\alpha$-bromoaryl)- $\mathrm{N}_{1}$-aryloacetyl-3-methyl-5pyrazolines. All these compounds were screened for their antifungal activity against Aspergillus niger and Aspergillus flavus. In general, antifungal activity [3] was found to increase. The different groups of the aldehyde moiety did not show any significant effect towards the antifungal activity. Keeping in mind the biological and clinical activity of pyrazolines and encouraged by our previous work [4], we now report the synthesis of some new benzothiazolo pyrazolines in order to study further the effect of bromine on their biological activity.

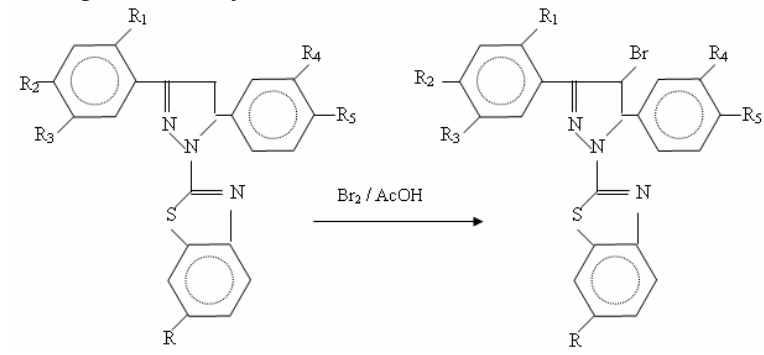

Where,

[1]. $\quad \mathrm{R}=\mathrm{CH}_{3}, \mathrm{R}_{1}=\mathrm{OH}, \mathrm{R}_{2}=\mathrm{H}, \mathrm{R}_{3}=\mathrm{CH}_{3}, \mathrm{R}_{4}=\mathrm{R}_{5}$

$=\mathrm{H}$

[II]. $\quad \mathrm{R}=\mathrm{OCH}_{3}, \mathrm{R}_{1}=\mathrm{OH}, \mathrm{R}_{2}=\mathrm{H}, \mathrm{R}_{3}=\mathrm{CH}_{3}, \mathrm{R}_{4}=$

$\mathrm{R}_{5}=\mathrm{H}$

[III]. $\quad \mathrm{R}=\mathrm{CH}_{3}, \mathrm{R}_{1}=\mathrm{H}, \mathrm{R}_{2}=\mathrm{CH}_{3}, \mathrm{R}_{3}=\mathrm{R}_{4}=\mathrm{H}, \mathrm{R}_{5}$ $=\mathrm{OCH}_{3}$

[IV]. $\quad \mathrm{R}=\mathrm{H}, \mathrm{R}_{1}=\mathrm{H}, \mathrm{R}_{2}=\mathrm{OCH}_{3}, \mathrm{R}_{3}=\mathrm{R}_{4}=\mathrm{R}_{5}=\mathrm{H}$

[V]. $\quad \mathrm{R}=\mathrm{R}_{1}=\mathrm{H}, \mathrm{R}_{2}=\mathrm{Cl}, \mathrm{R}_{3}=\mathrm{R}_{4}=\mathrm{R}_{5}=\mathrm{H}$

\section{Experimental}

All the Chemicals and solvents used in the present investigation were BDH products. Melting products were determined in open capillary tube and are uncorrected. IR spectra of the synthesized compounds were recorded in $\mathrm{KBr}$ on Perkin-Elmer 577 spectrophotometer and NMR spectra on an AC $300 \mathrm{~F}$ spectrophotometer with $\mathrm{CDCl}_{3}$ using TMS as internal reference (chemical shift in $\delta \mathrm{ppm}$ ).

[l].Synthesis of 3-(2-hydroxy-5-methylphenyl)-5phenyl-1-(6-methylbenzothiazolo)-4bromopyrazoline

3-(2'-hydroxy-5'-methylphenyl)-5-phenyl-1-(6methylbenzothiazolo) pyrozoline $(0.66 \mathrm{~g})$ was dissolved in hot acetic acid $(40 \mathrm{ml})$. After cooling bromine $(0.3 \mathrm{ml})$ in acetic acid $(10 \mathrm{ml})$ was added drop wise with constant shaking to ensure thorough mixing. The reaction mixture was then allowed to stand at room temperature overnight. The solid thus separated was filtered, washed with water and dried. Crystallization from a mixture of chloroform and alcohol (2:1) afforded light yellow crystals (0.69 g., M.P. $\left.248^{\circ} \mathrm{C}\right)$.

Molecular Formula: $\mathrm{C}_{24} \mathrm{H}_{20} \mathrm{~N}_{3} \mathrm{SOBr}$

Observed: $\mathrm{C}=72.86 ; \mathrm{H}=5.02 ; \mathrm{N}=11.44 \%$

Calculated: $\mathrm{C}=73.62 ; \mathrm{H}=5.49 ; \mathrm{N}=11.54 \%$

IR: $v_{\max }(\mathrm{KBr}): 3400,2940,1600,1550,1490,1460$, 1430, 1330, 1270, 1210, 1140, 1070, 900, 850, 830, $760,700,660,, 570$ and $550 \mathrm{~cm}^{-1}$.

$\operatorname{NMR}\left(\mathrm{CDCl}_{3}\right): \delta 2.20\left(6 \mathrm{H}, \mathrm{dd}, 2-\mathrm{CH}_{3}\right), \delta 3.30(1 \mathrm{H}, \mathrm{dd}$, $\mathrm{CH}), \delta 5.70(1 \mathrm{H}, \mathrm{d}, \mathrm{CH}), \delta 6.90$ to7.5 $(11 \mathrm{H}, \mathrm{m}, \mathrm{ArH}), \delta$ $10.60(1 \mathrm{H}, \mathrm{s}, \mathrm{OH})$.

[II]. Synthesis of 3-(2'-hydroxy-5-methylphenyl)-5phenyl-1-(6-methoxybenzothiazolo)-4-

\section{bromopyrazoline}

3-(2'-hydroxy-5'-methylphenyl)-5-phenyl-1-(6methoxybenzothiazolo) pyrozoline $(0.68 \mathrm{~g})$ was dissolved in hot acetic acid $(40 \mathrm{ml})$. After cooling bromine $(0.3 \mathrm{ml})$ in acetic acid $(10 \mathrm{ml})$ was added drop wise with constant shaking to ensure thorough mixing. The reaction mixture was occasionally shaken and was allowed to stand at room temperature overnight. The solid thus separated was filtered, washed with water and dried. Crystallization from a mixture of chloroform and alcohol (2:1) afforded pale yellow crystals ( 0.69 g., M.P. $\left.234-35^{\circ} \mathrm{C}\right)$.

Molecular Formula: $\mathrm{C}_{24} \mathrm{H}_{20} \mathrm{~N}_{3} \mathrm{SBrO}_{2}$

Observed: $\quad C=56.16 ; H=4.02 ; N=8.78 \%$

Calculated: $\mathrm{C}=56.54 ; \mathrm{H}=4.21 ; \mathrm{N}=8.86 \%$ 
IR: $v_{\max }(\mathrm{KBr}): 3300,2900,1600,1570,1530,1490$, $1450,1330,1270,1210,1180,1140,1060,1040$, $890,850,830,800,760,700,660,600$ and $560 \mathrm{~cm}^{-1}$. NMR $\left(\mathrm{CDCl}_{3}\right): \delta 1.60\left(3 \mathrm{H}, \mathrm{dd}, \mathrm{CH}_{3}\right), \delta 3.30(1 \mathrm{H}, \mathrm{dd}$, $\mathrm{CH}), \delta 3.80\left(3 \mathrm{H}, \mathrm{s}, \mathrm{OCH}_{3}\right), \delta 6.90$ to $7.70(10 \mathrm{H}, \mathrm{m}, \mathrm{Ar})$, $\delta 10.75(1 \mathrm{H}, \mathrm{s}, \mathrm{OH})$

[III]. Synthesis of 3-(4'-methylphenyl)-5-(4methoxyphenyl)-1-(6-methylbenzothiazolo)-4bromopyrazoline

3-(4'-methylphenyl)-5-(4-methoxyphenyl)-1-(6-

methylbenzothiazolo) pyrazoline $(0.67 \mathrm{~g})$ was dissolved in hot acetic acid $(40 \mathrm{ml})$. After cooling bromine $(0.3 \mathrm{ml})$ in acetic acid $(10 \mathrm{ml})$ was added drop wise with constant shaking to ensure thorough mixing. The reaction mixture was occasionally shaken and was allowed to stand at room temperature overnight. The solid thus separated was filtered, washed with water and dried. Crystallization from a mixture of chloroform and alcohol (2:1) afforded pale yellow crystals (0.69 g., M.P. $\left.159-60{ }^{\circ} \mathrm{C}\right)$.

Molecular Formula: $\mathrm{C}_{25} \mathrm{H}_{22} \mathrm{~N}_{3} \mathrm{SOBr}$

Observed: $\quad \mathrm{C}=60.16 ; \mathrm{H}=4.02 ; \mathrm{N}=8.08 \%$

Calculated: $\mathrm{C}=60.98 ; \mathrm{H}=4.47 ; \mathrm{N}=8.54 \%$

IR: $v_{\max }(\mathrm{KBr}): 3300,2900,1600,1530,1520,1460$, $1420,1320,1300,1270,1250,1230,1160,1140$, $1110,1030,930,910,840,800,760,680,630,560$ and $540 \mathrm{~cm}^{-1}$.

[IV]. Synthesis of 3-(4'-methoxyphenyl)-5-phenyl1-benzothiazolo)-4-bromopyrazoline

3-(4'-methoxyphenyl)-5-phenyl-1-benzothiazolo

pyrazoline $(0.62 \mathrm{~g})$ was dissolved in hot acetic acid $(40 \mathrm{ml})$. After cooling bromine $(0.3 \mathrm{ml})$ in acetic acid $(10 \mathrm{ml})$ was added drop wise with constant shaking to ensure thorough mixing. The reaction mixture was occasionally shaken and was allowed to stand at room temperature overnight. The solid thus separated was filtered, washed with water and dried. Crystallization from a mixture of chloroform and alcohol (2:1) afforded brick orange crystals (0.69 g., M.P. $\left.164-65^{0} \mathrm{C}\right)$.

Molecular Formula: $\mathrm{C}_{23} \mathrm{H}_{18} \mathrm{~N}_{3} \mathrm{SOBr}$

Observed: $\quad \mathrm{C}=60.16 ; \mathrm{H}=4.02 ; \mathrm{N}=8.08 \%$

Calculated: $\mathrm{C}=59.48 ; \mathrm{H}=3.88 ; \mathrm{N}=9.05 \%$

IR: $v_{\max }(\mathrm{KBr}): 2940,1600,1540,1500,1460,1370$, $1300,12240,1200,1170,1110,1060,1030,960$, $890,860,830,800,760,700,690,660$ and $550 \mathrm{~cm}^{-1}$.

[V]. Synthesis of 3-(4'-chlorophenyl)-5-phenyl-1benzothiazolo-4-bromopyrazoline

3-(4'-chlorophenyl)-5-phenyl-1-benzothiazolo-4-

pyrazoline $(0.65 \mathrm{~g})$ was dissolved in hot acetic acid $(40 \mathrm{ml})$. After cooling bromine $(0.3 \mathrm{ml})$ in acetic acid $(10 \mathrm{ml})$ was added drop wise with constant shaking to ensure thorough mixing. The reaction mixture was occasionally shaken and was allowed to stand at room temperature overnight. The solid thus separated was filtered, washed with water and dried. Crystallization from a mixture of chloroform and alcohol (2:1) afforded pale yellow crystals $(0.69 \mathrm{~g}$., M.P. $\left.191-92^{\circ} \mathrm{C}\right)$.
Molecular Formula: $\mathrm{C}_{22} \mathrm{H}_{15} \mathrm{~N}_{3} \mathrm{SBrCl}$

Observed: $\mathrm{C}=60.16 ; \mathrm{H}=4.02 ; \mathrm{N}=8.08 \%$

Calculated: $\mathrm{C}=60.55 ; \mathrm{H}=3.19 ; \mathrm{N}=8.95 \%$

IR: $v_{\max }(\mathrm{KBr}): 1600,1530,1500,1440,1390,1350$ $1330,1300,1270,1210,1180,1150,1090,1030$, $990,970,920,870,810,760,690,640,600,590$, and $550 \mathrm{~cm}^{-1}$.

NMR $\left(\mathrm{CDCl}_{3}\right) \delta 3.20(1 \mathrm{H}, \mathrm{dd}, \mathrm{C}-\mathrm{H}), \delta 5.80(1 \mathrm{H}, \mathrm{dd}, \mathrm{C}-$ $\mathrm{H}), \delta 7.20$ to $7.8(13 \mathrm{H}, \mathrm{m}, \mathrm{ArH})$

\section{Mass spectrum}

The important peaks with their intensities (in parenthesis) are tabulated as below.

469 (44.9\%), $468(30.5 \%), 466(16.9 \%), 465$ (50.8 $\%), 330$ (16.7\%), 329 (13.9\%), 327 (19.1\%), 307 (10.9\%), 303 (10.3\%), 287 (10.0\%), 239 (14.5\%), 229 (17.5), $228(29.0 \%), 227(28.4 \%), 226(23.1 \%)$, 225 (44.5), 224 (10.1\%), 146 (100.0\%), 132 (11.2 $\%), 120(11.9 \%), 110(10.6 \%), 104(19.8 \%), 103$ $(84.7 \%), 102(11.9 \%)$.

$[V I]$. Synthesis of $3-\left(4^{\prime}\right.$-methylphenyl)-5-(3, 4dimethoxyphenyl)-1-benzothiazolo-4-bromo pyrazoline

3-(4'-methylphenyl)-5-(3, 4-dimethoxyphenyl)-1benzothiazolopyrazoline $(0.73 \mathrm{~g})$ was dissolved in hot acetic acid $(40 \mathrm{ml})$. After cooling bromine $(0.3 \mathrm{ml})$ in acetic acid $(10 \mathrm{ml})$ was added drop wise with constant shaking to ensure thorough mixing. The reaction mixture was occasionally shaken and was allowed to stand at room temperature overnight. The solid thus separated was filtered, washed with water and dried. Crystallization from a mixture of chloroform and alcohol (2:1) afforded white crystals (0.69 g., M.P. 194-95 ${ }^{\circ} \mathrm{C}$ ).

Molecular Formula: $\mathrm{C}_{25} \mathrm{H}_{22} \mathrm{~N}_{3} \mathrm{SBrO}_{2}$

Observed: $\mathrm{C}=60.16 ; \mathrm{H}=4.02 ; \mathrm{N}=8.08 \%$

Calculated: $\mathrm{C}=59.05 ; \mathrm{H}=4.33 ; \mathrm{N}=8.26 . \%$

IR: $v_{\max }(\mathrm{KBr}): 3020,2940,1600,1540,1500,1450$, $1430,1360,1330,1300,1270,1250,12001140$, $1100,1090,1030,1010,950,870,820,770,740$, $700,610,570$, and $540 \mathrm{~cm}^{-1}$

\section{Results and Discussion}

The structures of these pyrazolines have been established by analytical analyses and spectral studies. PMR spectra of pyrazolines exhibits double doublets for each $-\mathrm{CH}_{2}$ proton between $\delta 3.25$ and 3.60 and $\delta 3.90$ and 4.00 , and double doublets between $\delta 5.25$ and $\delta 6.20$ for $-\mathrm{CH}$ proton. However, in PMR spectra of bromo benzothiazolopyrazolines the signal in range of $\delta 3.90$ to $\delta 4.00$ is absent $(\delta$ 3.14). This provides the conclusive evidence that electrophilic attack of bromine takes place at C-4 of the pyrazoline nucleus.

The mass spectra of 3-(4'-chlorophenyl)-5-phenyl-1benzothiazolo-4-bromopyrazoline exhibits the molecular ion peak at $\mathrm{m} / \mathrm{z} 468$, which is the molecular weight of the compound. The fragmentation pattern is as follows: 


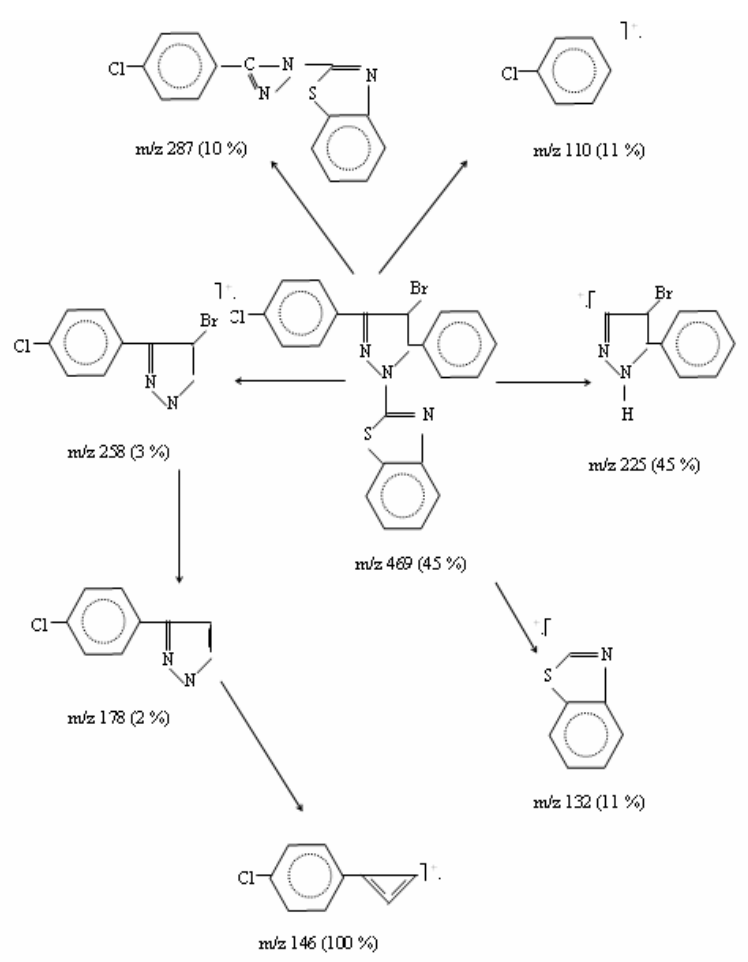

\section{References}

[1] Ankhiwala M. D. and Naik H. B. (1990) J. Indian Chem. Soc., 67, 258.

[2] Wolf M. (1968) Chem. Abstr., 68, 49599v.

[3] Suman S.P. and Bhel S.C. (1980) J. Indian Chem. Soc., LVII, 212.

[4] Kumar B., Pathak V., Rani S., Kant R. and Tiwari I.C. (2009) Int.J. Microbiol. Res., 1(2), 20. 